\title{
Optical characteristics of water at the mouth of the Ob River
}

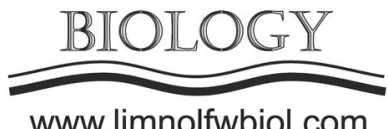

\author{
Akulova O.B.*, Bukaty V.I., Kirillov V.V.
}

Institute for Water and Environmental Problems, Siberian Branch of the Russian Academy of Sciences, 1, Molodezhnaya St., 656038 Barnaul, Russia

\begin{abstract}
As a result of the field studies (August 25 - September 1, 2020), new data were obtained on the optical characteristics of water at the Ob River mouth near the Salemal village (Yamal region, Yamal-Nenets Autonomous Okrug) during the lowest water level and the maximum development of hydrobiocenoses. We calculated the light attenuation coefficient $\varepsilon(\lambda)$ in the spectral range from 400 to $800 \mathrm{~nm}$, which varied from 1.5 to $21.5 \mathrm{~m}^{-1}$ during the study period, and the light absorption by yellow substance $\kappa_{y s}(\lambda)$ from 0.1 to $12.2 \mathrm{~m}^{-1}$. Concentrations of yellow substance $C_{y s}$ and chlorophyll $a$ Chl were determined. For instance, chlorophyll $a$ concentrations in water samples taken at different stations of the Ob River ranged from 12.5 to $22.7 \mathrm{mg} \cdot \mathrm{m}^{-3}$. The maximum content of chlorophyll $a$ in our case was recorded at a depth of $14 \mathrm{~m}$ (station 5.3 ), which was $22.7 \mathrm{mg} \cdot \mathrm{m}^{-3}$. The yellow substance concentration determined optically by the calculated yellow substance light absorption coefficient at wavelength $\lambda=450 \mathrm{~nm}$ ranged within 18.8 and $26.9 \mathrm{~g} \cdot \mathrm{m}^{-3}$ with an average value of $22.1 \mathrm{~g} \cdot \mathrm{m}^{-3}$. The average value of $\kappa_{v s}(\lambda)$ at $\lambda=450 \mathrm{~nm}$ over the study period was $4.7 \mathrm{~m}^{-1}$.
\end{abstract}

Keywords: spectral transparency of water, coefficients of light attenuation and absorption, colored dissolved organic matters, yellow substance, chlorophyll $a$, suspension, physical model, the Ob River

\section{Introduction}

Hydrooptical monitoring of natural water bodies widely uses measurements of spectral light attenuation coefficients $\varepsilon(\lambda)$, which are important optical characteristics containing information about the state of the aquatic environment. Their value depends on the content of optically active components in water, namely suspended solids, chlorophyll, yellow substance, and pure water (Kopelevich, 1983; Hong et al., 2004; Churilova et al., 2008; 2018; Man'kovsky, 2011; Levin, 2014; Efimova et al., 2016). Many tasks related to the assessment of the state of natural water require knowledge of the contribution of these components to $\mathcal{E}(\lambda)$ at different parts of the spectrum. The universality of the physical model of light attenuation in aquatic media used in this work allows to us expressly determine in real time the physical parameters of individual water components, in particular, the concentration and size of suspended solids particles, chlorophyll and yellow substance as well as to assess the trophicity of water bodies by their optical properties.

This work is devoted to the study of the optical characteristics of water at the control site "Salemal" in the last control section of the $\mathrm{Ob}$ River before the delta during the period from August 25 to September $1,2020$.

*Corresponding author.

E-mail address: akulova8282@mail.ru (O.B. Akulova)

Received: July 26, 2021; Accepted: September 9, 2021; Available online: October 05, 2021

\section{Materials and methods}

The object of the study is the mouth area of the Ob River, a compound natural complex located at the confluence of the Ob, Nadym, Pur, and Taz rivers into the Kara Sea, within which specific estuarine processes occur due to the interaction and mixing of river and sea waters as well as to delta formation processes. It includes the estuaries of the $\mathrm{Ob}, \mathrm{Nadym}$ and Taz rivers and the vast estuarial coastal area: Ob Bay and Taz Bay. The studies were carried out during the period of the lowest water level (according to the long-term average data of the State Committee for Hydrometeorology) and the maximum development of the river hydrobiocenoses (Yermolaeva et al., 2021). This combination of biotic and abiotic characteristics of the ecosystem determines the special ratio of their contribution to the optical properties of water.

The work was based on the results of treatment and analysis of 14 water samples taken at different depths of the Ob River study site. Observations were carried out at the mouth of the $\mathrm{Ob}$ River near the Salemal village, Yamal region, YNAO, from August 25 to September 1, 2020. Table shows the station numbers and sampling depths as well as their coordinates.

Light attenuation $\varepsilon(\lambda)$ and absorption by the yellow substance $\kappa_{y s}(\lambda)$ were measured in the

(C) Author(s) 2021. This work is distributed under the Creative Commons Attribution 4.0 License. 
laboratory in the wavelength range from 400 to $800 \mathrm{~nm}$ with an interval of $30 \mathrm{~nm}$ using a PE-5400UF single-beam spectrophotometer operating in the mode of measuring the spectral transparency (transmittance) of water. To determine the spectral transparency of water, we used a spectrophotometric method based on the principle of measuring the ratio of intensities of two light fluxes passing through the studied and reference media. A total of 336 measurements of spectral water transparency were carried out. Highly purified distilled water was used as the reference medium, a control sample, in relation to which the measurements were made. The light absorption by yellow substance $\kappa_{y s}(\lambda)$ was defined after measuring the spectral transparency of the water purified from aqueous suspension and chlorophyll $a$ through "Vladipor" membranes of MFASOS-1 type with a pore diameter of $0.22 \mu \mathrm{m}$. The values of $\varepsilon(\lambda)$ and $\kappa_{y s}(\lambda)$ (at the natural logarithmic base) were calculated by the formula, according to expression (1), excluding the spectral coefficient of pure water $\kappa_{p w}(\lambda)$.

$$
\varepsilon(\lambda)=\left(\frac{1}{L}\right) \cdot \ln \left(\frac{1}{T(\lambda)}\right)
$$

where $L$ is the cuvette length; $T(\lambda)=I(\lambda) / I_{0}(\lambda)-$ the transparency (transmittance) in relative units; $I(\lambda)$, $I_{0}(\lambda)$ - the intensity of transmitted and incident light, respectively, and $\lambda$ - the wavelength of light.

The absolute error of $\mathcal{E}(\lambda)$ and $\kappa_{y s}(\lambda)$ is induced by the spectrophotometer error during transmittance measurement $(\Delta T=0.5 \%)$ and the error measurement of a cuvette length. In the experiment, we used cuvettes $L=50 \mathrm{~mm}$ long. The maximum absolute error in defining $\mathcal{E}(\lambda)$ and $\kappa_{y s}(\lambda)$ amounted to $0.1 \mathrm{~m}^{-1}$.

The concentration of yellow substance $C_{y s}$ was determined from the expression given in (Man'kovsky, 2015)

$$
C_{y s}=\kappa_{y s}(450) / \kappa_{s p . y s}(450),
$$

where $\kappa_{s p . y s}(\lambda)$ is specific light absorption by yellow substance (Nyquist, 1979) at $\lambda=450 \mathrm{~nm}$. The effective value $\kappa_{y s}(\lambda)$ in formula (2) is also given by a similar calculation as above by summing $\kappa_{p w}(\lambda)$.

The nature of light absorption by yellow substance is due to electronic transitions in the molecules of organic compounds (Shifrin, 1983). The spectral dependence of light absorption by yellow substance $\kappa_{y s}(\lambda)$ is described by the exponential law (Kopelevich, 1983)

$$
\kappa_{y s}(\lambda)=e^{-\mu \cdot \lambda},
$$

where $\mu$ is the coefficient characterizing the slope of the spectral absorption curve, the value of which is not constant for different water bodies.

The relative spectral contribution of optically active components of water (suspension, yellow substance, chlorophyll, and pure water) to $\mathcal{E}(\lambda)$ was calculated using a modified semi-empirical spectral model of light attenuation (Akulova, 2015), which was first proposed by O.V. Kopelevich (Kopelevich, 1983). It looks as

$$
\varepsilon(\lambda)=\kappa_{c h l}(\lambda)+\kappa_{y s}(\lambda)+\sigma_{m o l}(\lambda)+\sigma_{s}(\lambda)+\kappa_{p w}(\lambda)
$$

where $\kappa_{c h l}(\lambda)$ and $\kappa_{y s}(\lambda)$ are spectral absorptions by chlorophyll and yellow substance, respectively; $\sigma_{\text {mol }}(\lambda)$ is spectral scattering by pure water; $\sigma_{s}(\lambda)$ is spectral dispersion by suspension, and $\kappa_{p w}(\lambda)$ is spectral absorption by pure water. The calculated attenuation, according to the formula (1), does not contain data on the attenuation by pure water $\varepsilon_{p w}(\lambda)=\kappa_{p w}(\lambda)+\sigma_{m o l}(\lambda)$. Thus, in (4), the values of $\varepsilon(\lambda)$ obtained due to spectrophotometer measurements should be summed up with the values of $\varepsilon_{p w}(\lambda)$ taken from the reference data (Smith and Baker, 1981; Pope and Fry, 1997). That was done in our research.

The chlorophyll absorption was calculated using the formula

$$
\kappa_{c h l}(\lambda)=\kappa_{s p . c h l}(\lambda) \cdot C_{c h l},
$$

where $C_{c h l}$ is the concentration of chlorophyll $a, \mathrm{mg} \cdot \mathrm{m}^{-}$ 3 , and $\kappa_{s p . c h l}(\lambda)$ is the specific chlorophyll absorption, $\mathrm{m}^{2} \cdot \mathrm{mg}^{-1}$ (Kopelevich, 1983). To calculate $\kappa_{p w}(\lambda)$, we used the tabular data from (Smith and Baker, 1981; Pope and Fry, 1997), and for $\sigma_{m o l}(\lambda)-$ (Smith and Baker, 1981).

As suggested in expression (4), spectral light attenuation is described via a three-parameter model. In contrast to the previous studies, where parameter $\sigma_{s}(\lambda)$ is determined experimentally, and $\kappa_{y s}(\lambda)$ is the difference between the measured $\mathcal{E}(\lambda)$ and the sum of other parameters, we propose an alternative approach. Since parameter $\kappa_{y s}(\lambda)$ was determined experimentally, spectral scattering by suspension $\sigma_{s}(\lambda)$ can be found from the expression (4) with the following formula:

$\sigma_{s}(\lambda)=\varepsilon(\lambda)-\left[\kappa_{c h l}(\lambda)+\kappa_{y s}(\lambda)+\sigma_{m o l}(\lambda)+\kappa_{p w}(\lambda)\right]$

The concentration of chlorophyll $a$ was found by a standard spectrophotometric method according to GOST 17.1.4.02-90. Relative transparency of $Z$ was measured using a Secchi disk.

\section{Results and discussion}

During the study period, the spectral light attenuation, $\mathcal{E}(\lambda)$, within $400-800 \mathrm{~nm}$ in water samples taken at different depths of the Ob River at the site near the village of Salemal during the lowest water levels varied from 1.5 to $21.5 \mathrm{~m}^{-1}$; the light absorption by yellow substance $\kappa_{y s}(\lambda)$ ranged from 0.1 to $12.2 \mathrm{~m}^{-1}$. The average value of $\kappa_{y s}$ at $\lambda=450 \mathrm{~nm}$ over the study period was $4.7 \mathrm{~m}^{-1}$. The concentration of yellow substance, $C_{y s}$, in water samples taken at 14 stations of the Ob River was in the range from 18.8 to $26.9 \mathrm{~g} \cdot \mathrm{m}^{-3}$ with an average of $22.1 \mathrm{~g} \cdot \mathrm{m}^{-3}$ (Table). 
Relative transparency measured by Secchi disk at different stations was $\sim 1.0 \mathrm{~m}$.

For example, Figure shows spectral curves of individual optical characteristics obtained for the surface layer of the Ob River station 1.1 (sample taken on August 27, 2020).

The same methodological approach based on the physical model of light attenuation in the aquatic environment was previously used to study the seasonal dynamics and spatial distribution of optical characteristics of river waters in Europe (Pawlak et al., 2003), the USA (Julian et al., 2008) and South America (Lobo et al., 2017).

Based on the results of two field trips to the Tapajós River Basin during the period of the highest water level, data on the total light attenuation, $\varepsilon(\lambda)$, in the range from 390 to $750 \mathrm{~nm}$ were obtained (Lobo et al., 2017). We defined $\varepsilon(\lambda)$ as the sum of light absorption, $\kappa(\lambda)$, and scattering, $\sigma(\lambda)$, by aquatic environment. In turn, the total absorption coefficient, $\kappa(\lambda)$, was determined as the sum of absorption coefficients by pure water, $\kappa_{p w}(\lambda)$, dispersed material, $\kappa_{s}(\lambda)$, and colored dissolved organic matter (yellow substance), $\kappa_{y s}(\lambda)$. Similarly, the total scattering coefficient was determined as the sum of $\sigma_{m o l}(\lambda)$ and $\sigma_{s}(\lambda)$, assuming that the total scattering is negligible due to the yellow substance light scattering coefficient, $\sigma_{y s}(\lambda)$. Consequently, we found that the values of $\kappa_{y s}(\lambda)$ for the presented five classes of water were in the narrow range from 2.0 to $3.5 \mathrm{~m}^{-1}$ at $\lambda=440 \mathrm{~nm}$. The values of light absorption by the yellow substance obtained for the Ob River at $\lambda=450 \mathrm{~nm}$ varied within a close range from 4.0 to $5.7 \mathrm{~m}^{-1}$.

Pawlak et al. (2003) presented seasonal variations of light attenuation, $\mathcal{E}(\lambda)$, in the $300-800 \mathrm{~nm}$ range at different sites of the Oder River in the Szczecin region. For example, for the first measurement site at a wavelength of about $\lambda=300 \mathrm{~nm}$, the value of $\varepsilon(\lambda)$ was up to $45.8 \mathrm{~m}^{-1}$ (fall), $30.32 \mathrm{~m}^{-1}$ (winter) and $54.16 \mathrm{~m}^{-1}$ (spring). At $\lambda=750 \mathrm{~nm}$, the value of $\varepsilon(\lambda)$ was $6.78 \mathrm{~m}^{-1}$ (fall), $1.99 \mathrm{~m}^{-1}$ (winter) and $7.38 \mathrm{~m}^{-1}$ (spring).

Julian et al. (2008) also presented the data on

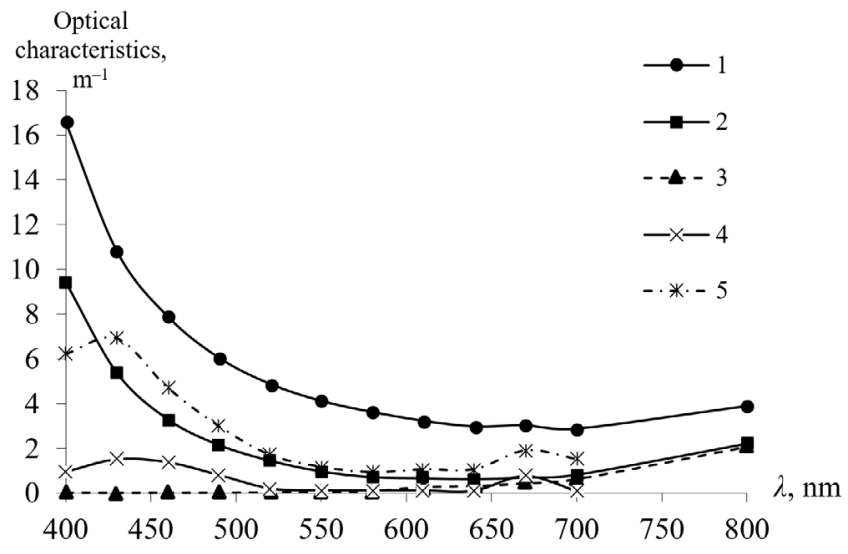

Fig. Spectral dependencies of optical characteristics 1 - light attenuation coefficient $\varepsilon(\lambda) ; 2$ - light absorption by yellow substance $\kappa_{v s}(\lambda) ; 3$ - attenuation by pure water $\varepsilon_{p w}(\lambda) ; 4-$ light absorption by chlorophyll $a \kappa_{c h l}(\lambda) ; 5$ - spectral dispersion by suspension $\sigma_{s}(\lambda)$

the total light attenuation $\varepsilon(\lambda)$ obtained for different sections of the Deep River at Glendon (DR), Big Spring Creek at Big Spring (BSC), the Baraboo River at La Valle (BR), and the Wisconsin River at Muscoda (WR), which accounted to $5.78 \mathrm{~m}^{-1}, 2.73 \mathrm{~m}^{-1}, 29.26 \mathrm{~m}^{-1}$, and $15.71 \mathrm{~m}^{-1}$, respectively. We also determined the yellow substance light absorption at $\lambda=440 \mathrm{~nm}$, which was as follows: for DR River $-4.44 \mathrm{~m}^{-1}$, BSC $-0.41 \mathrm{~m}^{-1}$, BR $1.60 \mathrm{~m}^{-1}$, and $\mathrm{WR}-2.36 \mathrm{~m}^{-1}$.

The calculation of the spectral contribution of the main optically active components of river water to spectral light attenuation, $\varepsilon(\lambda)$, at various sampling sites of the Ob River has shown that the yellow substance and suspension have the greatest optical influence on the total light attenuation. Here, the values of $\mathcal{E}(\lambda)$ and $\kappa_{y s}(\lambda)$ are given at the natural logarithmic base.

The largest contribution of yellow substance at $\lambda=430 \mathrm{~nm}$ was recorded in the surface layer of station 2.1 where it was $61.1 \%$. At a wavelength of $550 \mathrm{~nm}$, the yellow substance contribution varied from $21.3 \%$ (station 5.3) to $70.0 \%$ (station 3.2 ). At $\lambda=670 \mathrm{~nm}$, the largest contribution of yellow substance was recorded at a depth of $5 \mathrm{~m}$ (station 3.2) and amounted to $39.4 \%$.

Table. Light absorption by yellow substance $\left(\kappa_{y s}\right)$, the concentration of yellow substance $\left(C_{y s}\right)$ and chlorophyll $a(C h l)$ at different stations of the Ob River

\begin{tabular}{|c|c|c|c|c|c|}
\hline $\begin{array}{l}\text { Station } \\
\text { number }\end{array}$ & Depth, m & Coordinate & $\begin{array}{c}\kappa_{y s}(450) \\
\mathrm{m}^{-1}\end{array}$ & $C_{y s}, \mathbf{g} \cdot \mathbf{m}^{-3}$ & $\begin{array}{c}\text { Chl, } \\
\mathrm{mg} \cdot \mathrm{m}^{-3}\end{array}$ \\
\hline 1.1 & 0 & N 6646’56,6» E 6857'37,5» & 4.0 & 18.8 & 17.0 \\
\hline 1.2 & 2 & N 6646’56,6» E 6857'37,5» & 4.4 & 20.9 & 16.2 \\
\hline 1.3 & 8 & N 6646’56,6» E 6857'37,5» & 4.4 & 20.7 & 22.6 \\
\hline 2.1 & 0 & N 66 $46^{\prime} 49,5 »$ E $68^{\circ} 57^{\prime} 35,3 »$ & 4.7 & 22.0 & 19.2 \\
\hline 2.2 & 5 & $\mathrm{~N} 66^{\circ} 46^{\prime} 49,5 » \mathrm{E} 68^{\circ} 57^{\prime} 35,3 »$ & 4.7 & 22.4 & 20.5 \\
\hline 2.3 & 20 & $\mathrm{~N} 66^{\circ} 46^{\prime} 49,5 »$ E $68^{\circ} 57^{\prime} 35,3 »$ & 4.4 & 20.9 & 17.7 \\
\hline 3.1 & 0 & $\mathrm{~N} 66^{\circ} 46^{\prime} 39,1 » \mathrm{E} 68^{\circ} 57^{\prime} 36,1 »$ & 4.5 & 21.2 & 17.9 \\
\hline 3.2 & 5 & 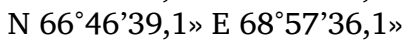 & 5.7 & 26.9 & 20.3 \\
\hline 3.3 & 25 & $\mathrm{~N} 66^{\circ} 46^{\prime} 39,1 » \mathrm{E} 68^{\circ} 57^{\prime} 36,1 »$ & 5.0 & 23.6 & 16.5 \\
\hline 4.1 & 0 & $\mathrm{~N} 66^{\circ} 46^{\prime} 32,6 » \mathrm{E} 68^{\circ} 57^{\prime} 24,4 »$ & 4.9 & 22.9 & 12.5 \\
\hline 4.2 & 5 & N 6646’32,6» E 6857’24,4» & 4.8 & 22.8 & 21.6 \\
\hline 4.3 & 20 & N 6646’32,6» E 68 57'24,4» & 4.8 & 22.8 & 18.1 \\
\hline 5.1 & 0 & 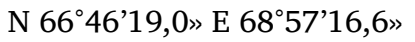 & 4.6 & 21.7 & 20.2 \\
\hline 5.3 & 14 & $\mathrm{~N} 66^{\circ} 46^{\prime} 19,0 » \mathrm{E} 68^{\circ} 57^{\prime} 16,6 »$ & 4.5 & 21.3 & 22.7 \\
\hline
\end{tabular}


Suspension makes the largest contribution to the light attenuation at $\lambda=430 \mathrm{~nm}$ at station 2.3 and is just over $51 \%$. The suspension contribution increases to $71.7 \%$ at the same station at $\lambda=550 \mathrm{~nm}$. At the other stations, the suspension contribution was within a wide range from 26.3 to $74.7 \%$. At $\lambda=670 \mathrm{~nm}$, the suspension contribution at the $\mathrm{Ob}$ River varied from $22.8 \%$ (station 3.2 ) to $74.7 \%$ (station 2.3 ).

Pure water makes an insignificant contribution to the light attenuation at $\lambda=430 \mathrm{~nm}$ at all stations and is less than $0.1 \%$. However, it increases sharply in the long-wave region where the values reach $20.7 \%$ at $\lambda=670 \mathrm{~nm}$.

The contribution from chlorophyll at $\lambda=430 \mathrm{~nm}$ ranged from $8.3 \%$ (station 4.1 ) to $17.5 \%$ (station 1.3 ), while at $\lambda=550 \mathrm{~nm}$, it varied from $1.6 \%$ (station 2.3 ) to $3.7 \%$ (station 1.3). At $\lambda=670 \mathrm{~nm}$, the maximum chlorophyll contribution was observed at station 2.1, accounting for $36.5 \%$.

Molecular light scattering by pure water in the investigated spectral range is responsible for a small contribution $(0.1 \%)$.

Thus, for the Ob River waters, yellow substance and suspension appeared to be the most significant optically active components affecting the total light attenuation.

Chlorophyll $a$ content at the Ob River site near the Salemal village was studied on August 27, 2020, at 14 stations and different layers (from the surface to $25 \mathrm{~m}$ ). During the observation period, chlorophyll $a$ concentration at different sites ranged from 12.5 to $22.7 \mathrm{mg} \cdot \mathrm{m}^{-3}$ (Table). In our case, the maximum chlorophyll $a$ concentration was recorded at a depth of $14 \mathrm{~m}$ (station 5.3) and amounted to $22.7 \mathrm{mg} \cdot \mathrm{m}^{-3}$. The amplitude and the maximum concentration of the main photosynthetic pigment of algae, chlorophyll, indicate that phytoplankton development at the $\mathrm{Ob}$ mouth at the end of August corresponds to highly eutrophic water bodies.

The development of phytoplankton in the $\mathrm{Ob}$ River at the end of August was high; in terms of its biomass, the water body in this period of the year can be classified as highly eutrophic according to I.S. Trifonova's trophicity scale (Trifonova, 1990), more than $10 \mathrm{~g} \cdot \mathrm{m}^{-3}$. This also agrees with chlorophyll $a$ content in the range from 12.5 to $22.7 \mathrm{~g} \cdot \mathrm{m}^{-3}$.

\section{Conclusions}

New data were obtained on the optical characteristics of water at the mouth section of the $\mathrm{Ob}$ River during the period of the lowest water level and the maximum development of hydrobiocenoses. It was found that light attenuation $\varepsilon(\lambda)$ in the spectral range from 400 to $800 \mathrm{~nm}$ varied widely from 1.5 to 21.5 $\mathrm{m}^{-1}$; the index of light absorption by yellow substance $\kappa_{y s}(\lambda)$ was from 0.1 to $12.2 \mathrm{~m}^{-1}$. The mean relative transparency measured with the Secchi disk at different stations was $\sim 1.0 \mathrm{~m}$. The concentrations of yellow substance in water samples ranged from 18.8 to 26.9 $\mathrm{g} \cdot \mathrm{m}^{-3}$ with an average value of $22.1 \mathrm{~g} \cdot \mathrm{m}^{-3}$. New data on chlorophyll $a$ content in the studied sites of the Ob river were obtained. The maximum content of chlorophyll $a$ was recorded at a depth of $14 \mathrm{~m}$ and accounted for $22.7 \mathrm{mg} \cdot \mathrm{m}^{-3}$. It was found that the yellow substance and suspended solids were the most significant optically active components affecting the total light attenuation in the Ob River waters. The results obtained for the mouth of the Ob River agree with the data for other world rivers studied with the methodological approach based on the physical model of light attenuation in aquatic environments. This allows us to make recommendations for the inclusion of hydro-optical characteristics in the program of monitoring and forecasting the dynamics of aquatic ecosystems in the region under climate change and increasing anthropogenic load due to the use of natural resources.

\section{Acknowledgments}

The work was carried according to Agreement No. 3-2.4 / 2020 with the Non-Profit Partnership "Russian Center for Arctic Development" dated August 18, 2020, for conducting "Integrated research of the Gulf of the $\mathrm{Ob}$ within the framework of the "Environmental safety of the Ob-Irtysh River basin" project implementation in 2020", as well as within the framework of the state assignment for IWEP SB RAS (State registration of projects Nos AAAA-A17-117041210244-5 and AAAA-A17-117041210241-4).

\section{Conflict of interests}

The authors declare no conflict of interests.

\section{References}

Akulova O.B. 2015. Development of methods and a measuring computer system for assessing ecologically significant hydro-optical characteristics of freshwater reservoirs (by the example of lakes in Altai Krai). Cand. Sc. Dissertation, Institute for Water and Environmental Problems SB RAS, Barnaul, Russia. (in Russian)

Churilova T.Ya., Suslin V.V., Ryl'kova O.A. 2008. Parametrizatsiya pogloshcheniya sveta osnovnymi opticheski aktivnymi komponentami v Chernom more [Parameterization of light absorption by main optically active components in the Black sea]. Ekologicheskaya Bezopasnost' Pribrezhnoy i Shel'fovoy Zon i Kompleksnoe Ispol'zovanie Resursov Shel'fa [Environmental Safety of Coastal and Shelf Zones and Integrated Use of Shelf Resources] 16: 190-201. (in Russian)

Churilova T.Ya., Moiseeva N.A., Latushkin A.A. et al. 2018. Preliminary results of bio-optical investigations at Lake Baikal. Limnology and Freshwater Biology 1(1): 58-61. DOI: 10.31951/2658-3518-2018-A-1-58

Efimova V.T., Moiseeva N.A., Churilova T.Ya. et al. 2016. Pogloshchenie sveta opticheski aktivnymi komponentami sredy $\mathrm{v}$ zone fotosinteza glubokovodnoy chasti Chernogo morya (Sentyabr' 2015 goda) [Light absorption by optical active components of environment in the photosynthesis zone in the Black sea deep-water (September, 2015)]. Ekologicheskaya Bezopasnost' Pribrezhnoy i Shel'fovoy Zon Morya [Ecological Safety of Coastal and Shelf Zones of Sea] 4: 30-34. (in Russian) 
Hong Y.U., Qiming C.A.I., Jinglu W.U. 2004. Study on optical properties of unpigmented suspended particles, yellow substance and phytoplankton algae in Taihu Lake. Chinese Journal of Oceanology and Limnology 22: 24-33. DOI: $10.1007 / \mathrm{BF} 02842797$

Julian J.P., Doyle M.W., Powers S.M. et al. 2008. Optical water quality in rivers. Water Resources Research 44. DOI: 10.1029/2007WR006457

Kopelevich O.V. 1983. Low-parametrical model of optical properties of seawater. In: Monin A.S. (Ed.), Optika okeana. T. 1. Fizicheskaya optika okeana [Ocean optics. Vol. 1. Physical optics of the ocean]. Moscow: Nauka, pp. 208-235. (in Russian)

Levin I.M. 2014. Few-parameter optical models of seawater inherent optical properties. Fundamental'naya i Prikladnaya Gidrofizika [Fundamental and Applied Hydrophysics] 7(3): 3-22. (in Russian)

Lobo F.L., Costa M.P.F., Novo E.M. et al. 2017. Effects of small-scale gold mining tailings on the underwater light field in the Tapajós River Basin, Brazilian Amazon. Remote Sensing 9. DOI: $10.3390 /$ rs9080861

Man'kovsky V.I. 2011. Spectral contribution of the seawater components in the attenuation coefficient of directed light in the surface Mediterranean waters. Physical Oceanography 21(5): 305-319.

Man'kovsky V.I. 2015. Yellow substancein surface waters of the eastern part of the Tropical Atlantic. Physical Oceanography 3: 50-57. DOI: 10.22449/1573-160X-2015-3-50-57
Nyquist G. 1979. Investigation of some optical properties of seawater with special reference to lignin sulfonates and humic substances. PhD Thesis, Göteborg University, Sweden.

Pawlak B., Gąsowski R., Banaszak A. et al. 2003. Seasonal changes of light attenuation coefficient in selected points of the Oder River in the Szczecin Region, Poland. Polish Journal of Environmental Studies 12(2): 221-226.

Pope R.M., Fry E.S. 1997. Absorption spectrum (380 $700 \mathrm{~nm}$ ) of pure water. II. Integration cavity measurements. Applied Optics 36(33): 8710-8723. DOI: 10.1364/ AO.36.008710

Shifrin K.S. 1983. Vvedenie v optiku okeana [Introduction to ocean optics]. Leningrad: Gidrometeoizdat. (in Russian)

Smith R.C., Baker K.S. 1981. Optical properties of the clearest natural waters (200-800 nm). Applied Optics 20(2): 177-184. DOI: $10.1364 /$ AO.20.000177

Trifonova I.S. 1990. Ekologiya i suktsessiya ozernogo fitoplanktona [Ecology and succession of lake phytoplankton]. Leningrad: Nauka. (in Russian)

Yermolaeva N., Dvurechenskaya S., Kirillov V. et al. 2021. Dependence of long-term dynamics of zooplankton in the $\mathrm{Ob}$ River on interannual changes in hydrological and hydrochemical parameters. Water 13(14). DOI: 10.3390/ w13141910 